\title{
Renewing the system Thinking broadly about equity, diversity, and inclusion in scholarly communication
}

$\mathbf{T}$ he ACRL Board of Directors recently articulated a new core commitment of our strategic plan, the Plan for Excellence. Along with the association's core purpose, "[t]o lead academic and research librarians and libraries in advancing learning and scholarship," 1 and our core organizational values, which include visionary leadership, responsible stewardship of resources, and the values of higher education and intellectual freedom, we have made an explicit commitment to equity, diversity, and inclusion (EDI).

As part of this commitment, we undertake to

acknowledge and address historical racial inequities; challenge oppressive systems within academic libraries; value different ways of knowing; and identify and work to eliminate barriers to equitable services, spaces, resources, and scholarship. ${ }^{2}$

This is no small pledge. In making it, we are acknowledging that we cannot accomplish our core purpose or realize our future visions without addressing fundamental matters of social justice and inequities that are both historical and current. Further, we recognize that this work "permeates the work of the Association, cutting across all ACRL sections, committees, interest and discussion groups, and communities of practice." ${ }^{3}$

In other words, we can't succeed in any of our endeavors unless and until we resolve the longstanding inequities in our association, institutions, and profession.

It may seem that our work to revise the scholarly communication system inherently moves us toward this goal. After all, discussions of equity and inclusion have long infused our work in scholarly communication, and particularly in the areas of open educational resources (OER) and open access.

As Rajiv Jhangiani (not a librarian but a powerful voice of the OER movement and an active ally to librarians' work in this area) notes:

[t]he open education movement wants to be a force for equity. The argument is straightforward and powerful: Widen access to educational resources and those who disproportionately suffer at the hands of the exploitative business models of commercial publishers will disproportionately benefit, in both economic and educational terms. ${ }^{4}$

This is a persuasive statement in support of opening up scholarly and educational materials to a broader audience. It suggests that in pursuing these goals, we are by definition

Karen Munro is associate dean of libraries, learning, and research services at Simon Fraser University and 2019-20 ACRL President, email: kemunro@sfu.ca

๑) 2019 Karen Munro 
championing a more equitable, inclusive, and diverse system - and in some respects that is true. But librarians, activists, and scholars are increasingly pointing out that "going open" is not enough. There are other aspects of EDI to consider as we re-envision scholarly communication overall, some of them not as widely recognized or well-entrenched in our culture, but equally important to consider if we wish to build truly transformative systems.

\section{Creating an equitable scholarly communication system}

Our core commitment to EDI asks us to address historic inequities, challenge oppressive systems, and value different ways of knowing. In short, we pledge to rethink the structures and systems underlying our work, including our most basic assumptions about how that work is generated. If we wish to be creators and stewards of a truly equitable scholarly communication system, we must consider the conditions in which scholarship is created. Before any research can be made open, it must come into existence. Even a brief investigation into scholarly systems reveals that not all research questions are valued equally. Neoliberalism plays a role, as do the pre-existing intellectual structures and biases of most institutions of higher education. Under the aegis of neoliberalism, "[u]niversities, faculty members, and students alike are 'incentivized' to focus on hyperproductivity and high returns on investment, and to minimize risk." 5 This can severely constrain the avenues of inquiry that researchers can realistically pursue.

Setting aside the challenges of neoliberalism to the modern research university, academe itself places limits on what constitutes legitimate research. Sometimes this happens subtly, as when students look to their mentors to help them define their research project, thus running the risk of reproducing the same kind of research for which the mentor or department is already known. Sometimes it's more egregious.

In a 2012 blog post published in The Chronicle of Higher Education, Naomi
Schaefer Riley publicly ridiculed the titles and topics of students graduating in the first cohort of Black Studies at Northwestern University, arguing that they were evidence of the illegitimacy of the entire discipline. Tressie McMillan Cottom's resounding rebuke to that post points out how damaging and silencing this type of attack can be.

"These scholars did not deserve to be publicly attacked in the largest academic news publication for daring to be visible and black with a dissertation title that Schaefer Riley finds hilarious." ${ }^{6}$

If we truly expect to carry out our pledge to value different ways of knowing, we must acknowledge that academe is not neutral, and that the existing mechanisms of scholarly communication play a role in this. We must understand that junior scholars in particular must publish strategically, in high-impact journals, in order to achieve promotion and tenure. If we rebuild our structures only to retain a system that automatically inhibits the exploration of new ideas and avenues of inquiry, which devalues questions of interest to women, or African Americans, or the global South, for instance, because they are not as "strategic" or "rewarding" as other topics, then we will have failed.

\section{Considering the cost of open}

One of our profession's most fundamental assumptions about the scholarly landscape is that open is good. Few of us would deny that the value of "open" is critical to a new scholarly communication ecosystem. But as tempting as it is to think that making content openly accessible is enough, we must pause to consider the cost and types of labor that make "open" possible. The path that any work takes to publication is long and complex, involving librarians as well as researchers, editors, reviewers, typesetters, graphic designers, programmer-developers, and so on. Increasingly, sharp-eyed labor advocates are asking us to consider how workers are compensated for duties that are not yet universally understood or valued by universities and publishers. 
Writer and educator Audrey Watters asks, "When we think about 'open' and labor, who do we imagine doing the work? What is the work we imagine being done? Who pays? Who benefits? (And how?)" ${ }^{\prime}$ Sessional, adjunct, or unaffiliated scholars may find it critically difficult or impossible to contribute the kinds of unpaid labor that drive the systems of open scholarly communication, and therefore find themselves professionally sidelined. Even librarians, faculty, and others in paid positions may find themselves doing critical open work "off the side of their desk," or in a precarious contract capacity, because this work is un- or under-recognized in traditional administrative and financial systems. As we expand our ambitions to make more content openly accessible to an ever-broadening audience, we must consider if and how we will create hard-funded, continuing positions that are well-supported by colleagues and institutions overall.

\section{The implications of digital redlining}

Ideation, inquiry, and invisible labor may seem a little outside the remit of many librarians working in scholarly communication. More often, our duties and concerns lie in areas such as stewardship, hosting, classification, discovery, and maintenance. But even here, there is much to consider to create truly equitable systems. Scholars have begun to alert us to the implications of "digital redlining": that is, practices and systems that create or maintain digital, technological, and data- or information-related inequities based on users' class, race, or other identity.

The term redlining, comes originally from the practice of banks and insurance companies marking neighborhoods on city maps with red to designate them as undesirable, high-risk, and low-worth. Residents of redlined neighborhoods, who were predominantly people of color, were denied bank loans or home insurance, or charged higher rates than the primarily white residents of other areas. Their immediate financial circumstances, as well as their ability to build long-term wealth, suffered greatly as a result. ${ }^{8}$
Many neighborhoods across the United States continue to be divided along racial lines.

In the digital context, a variety of practices continue to perpetuate or create similar inequities. Safiya Umoja Noble points out the inequities built into many digital algorithms, including those that drive the search engines that reveal scholarly output to the world. As Noble points out, "[o]n the Internet and in our everyday uses of technology, discrimination is also embedded in computer code and, increasingly, in artificial intelligence technologies that we are reliant on, by choice or not." Noble points out that the same human biases that systematically exclude people of color from influential positions in the technology industry are enshrined in supposedly neutral technologies, such as the algorithms driving search results. These algorithms perpetuate inequality in ways that many Internet users don't understand. ${ }^{10}$

The scholarly communication infrastructure of the future is digital, both entwined with and reliant on any number of platforms, search engines, APIs, and other technologies that make scholarly content discoverable and available to researchers. Clearly, as scholarly communication continues to evolve in the digital context, we must engage in diligent critique of the underlying technologies of presentation and discovery to avoid reproducing the racial, socioeconomic, and other biases of the world around us. If we truly wish to "identify and work to eliminate barriers to equitable services, spaces, resources, and scholarship," we must be alert and informed users not only of the systems we create and license, but of the larger digital scholarly landscape.

Revising scholarly communication systems carries far broader EDI implications than I can address here. At a glance, the challenge can seem overwhelming. Is it truly possible to think about all of these different problemssome of them vast, far-reaching, and outside of our direct control-before we get going on a project? Must we take so many considerations into account before we start a new project, or pop the hood on an existing one? I believe the short answer is: yes. If we truly want to build 
a more just and equitable world for scholarly knowledge, we need to think broadly about our work from its earliest stages, and take active steps to remedy the harm we might otherwise build into our work.

Fortunately, we do not lack for thoughtful, creative, and courageous colleagues to help us see the terrain, and to suggest the best ways through it. Conversations around each of these questions are ongoing in our literature, at our conferences, and on social media. Within ACRL, the Research Agenda for Scholarly Communications and the Research Environment offers an excellent, comprehensive overview of the issues facing us in revising our scholarly communication systems. ${ }^{11}$ Outside of our association, MIT has shared its Grand Challenges-Based Research Agenda for Scholarly Communication and Information Science, outlining similar concerns. ${ }^{12}$ Any of these offers an excellent starting point for learning more about these questions, and contributing to the conversation.

If we are serious about our core commitment to EDI, I believe we must be humble and curious, as well as spirited. We as academic librarians - a profession that is still more than $80 \%$ white $^{13}$ after decades of attempting to diversify - must adopt an attitude of friendly curiosity and openness toward our own established opinions, our own assumed expertise, and (inevitably) our own mistakes and failures. If we cannot do this, we will recreate in the landscape of scholarly communication the same inequities that have deprived us all of the full spectrum of human knowledge, contribution, and advancement. Fundamentally, if we want to succeed in revolutionizing our systems of learning, we must, as the saying goes, "be the change want to see in the world." We must be as open, fair, and durable as the systems we wish to create.

\section{Notes}

1. "ACRL Plan for Excellence," ACRL, November 29, 2018, accessed May 21, 2019, www. ala.org/acrl/aboutacrl/strategicplan/stratplan.

2. Ibid.

3. Ibid.
4. "OER, Equity, and Implicit Creative Redlining," Rajiv Jhangiani, PhD, April 7, 2018, accessed May 21, 2019, http://thatpsychprof. com/oer-equity-and-implicit-creative-redlining/.

5. Frances Henry, Carl E. James, Peter S. Li, Audrey Kobayashi, Malinda Sharon Smith, Howard Ramos, and Dua Enakshi, The Equity Myth: Racialization and Indigeneity at Canadian Universities (Vancouver: UBC Press, 2017), 13.

6. "The Inferiority of Blackness as a Subject," Tressiemc, May 2, 2012, accessed May 21, 2019, https://tressiemc.com /uncategorized/the-inferiority-of-blackness -as-a-subject/.

7. Open but Not Free: Invisible Labour in Open Scholarship: 2018-10-24 | SFU Library, accessed May 21, 2019, https://www.lib.sfu. ca/help/publish/scholarly-publishing/33758.

8. Alexis C. Madrigal, "The Racist Housing Policy That Made Your Neighborhood," The Atlantic, April 30, 2015, accessed May 21, 2019, https://www.theatlantic.com/business /archive/2014/05/the-racist-housing-policy -that-made-your-neighborhood/371439/.

9. Safiya Umoja Noble, Algorithms of Oppression: How Search Engines Reinforce Racism (New York: New York University Press, 2018), 1.

10. Safiya Umoja Noble, "Social Inequality Will Not Be Solved By an App," Wired, March 4, 2018, accessed May 21, 2019, https://www.wired.com/story/social -inequality-will-not-be-solved-by-an-app/.

11. Open and Equitable Scholarly Communications: Creating a More Inclusive Future, prepared by Nancy Maron and Rebecca Kennison with Paul Bracke, Nathan Hall, Isaac Gilman, Kara Malenfant, Charlotte Roh, and Yasmeen Shorish (Chicago: ACRL, 2019).

12. Micah Altman and Chris Bourg, "A Grand Challenges-Based Research Agenda for Scholarly Communication and Information Science," MIT Grand Challenge PubPub Participation Platform, accessed May 21, 2019, https://grandchallenges.pubpub.org/pub/final.

13. "Member Demographics Study," Tools, Publications \& Resources, July 18, 2017, accessed May 21, 2019, www.ala.org /tools/research/initiatives/membershipsurveys. 72 